\title{
The Impacts of Quality Work Life and Occupational Commitment on Job-Hopping Behavior of Chefs in 4 and 5 Star Rated Hotels in Malaysia
}

Muaz Azinuddin, Nur Shahirah Mior Shariffuddin, Wan Mohd Adzim Wan Mohd Zain, Ahmad Puad Mat Som

To Link this Article: http://dx.doi.org/10.6007/IJARBSS/v11-i9/10843 DOI:10.6007/IJARBSS/v11-i9/10843

Received: 04 July 2021, Revised: 30 July 2021, Accepted: 20 August 2021

Published Online: 26 September 2021

In-Text Citation: (Azinuddin et al., 2021)

To Cite this Article: Azinuddin, M., Shariffuddin, N. S. M., Zain, W. M. A. W. M., \& Som, A. P. M. (2021). The Impacts of Quality Work Life and Occupational Commitment on Job-Hopping Behavior of Chefs in 4 and 5 Star Rated Hotels in Malaysia. International Journal of Academic Research in Business and Social Sciences, 11(9), 1432-1444.

Copyright: (c) 2021 The Author(s)

Published by Human Resource Management Academic Research Society (www.hrmars.com) This article is published under the Creative Commons Attribution (CC BY 4.0) license. Anyone may reproduce, distribute, translate and create derivative works of this article (for both commercial and non-commercial purposes), subject to full attribution to the original publication and authors. The full terms of this license may be seen at: http://creativecommons.org/licences/by/4.0/legalcode

Vol. 11, No. 9, 2021, Pg. 1432 - 1444

Full Terms \& Conditions of access and use can be found at http://hrmars.com/index.php/pages/detail/publication-ethics 


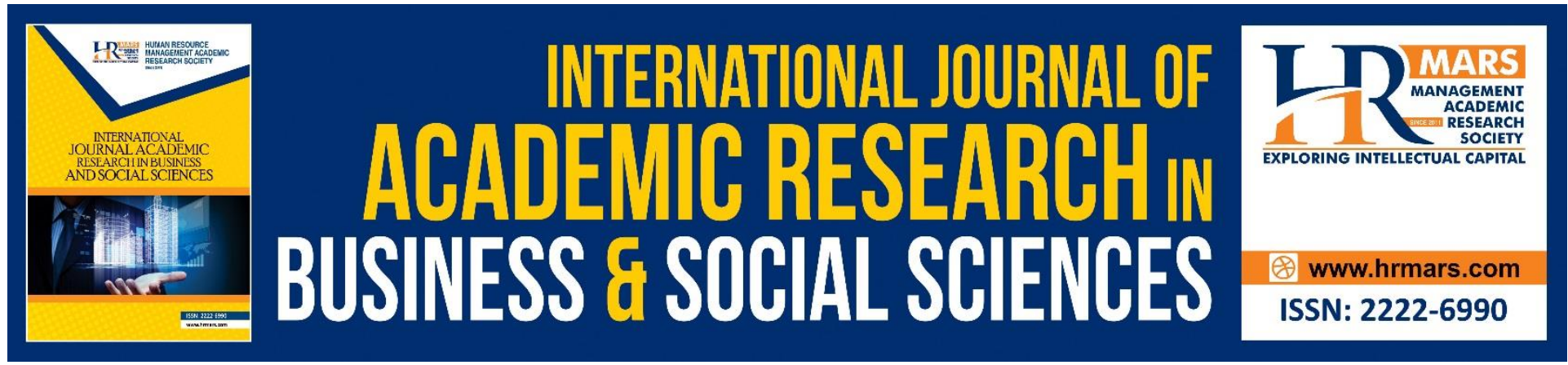

\title{
The Impacts of Quality Work Life and Occupational Commitment on Job-Hopping Behavior of Chefs in 4 and 5 Star Rated Hotels in Malaysia
}

\author{
Muaz Azinuddin, Nur Shahirah Mior Shariffuddin, Wan Mohd \\ Adzim Wan Mohd Zain, Ahmad Puad Mat Som \\ Faculty of Applied Social Sciences, Universiti Sultan Zainal Abidin, Kuala Nerus, Terengganu, \\ Malaysia \\ Email: muazazinuddin@unisza.edu.my
}

\begin{abstract}
The employees' retention in the hotel organizations is crucial as they are the greatest foundation for the organizational success. However, hotels in Malaysia are beleaguered by high turnover rates especially among the chefs who are looking to job hop to secure better opportunities. Thus, it is the aim of this research to determine the potential predictors of jobhopping behavior among the Malaysian chefs in the shape of quality work life and occupational commitment. The data were gathered at four- and five-star hotels located in the Golden Triangle of Kuala Lumpur. Based on the results of the regression analysis, it can be revealed that occupational commitment is the best predictor on job-hopping behavior of chefs compared to the influence of quality work life. The outcome of this study plays a significant bearing for decision makers to heighten the important dimensions of quality work life and occupational commitment in curbing the phenomenon of job-hopping and addressing the issue of high turnover among the workforce in the Malaysia hotel industry.
\end{abstract}

Keywords: Quality Work Life, Occupational Commitment, Job-Hopping Behaviour, Hotel, Chefs

\section{Introduction}

Tourism industry in Malaysia has contribute significantly to the economy before the spread of Covid-19 as it accounted for 15.9 percent of Gross Domestic Product and 23.6 percent of total employment in 2019 (Department of Statistics Malaysia, 2019). From this, the tourism industry in Malaysia has supplied 3.6 million employments and made RM86.1 billion in income from international and domestic tourism (Department of Statistics Malaysia, 2019; Tourism Malaysia, 2021). This solid performance by the tourism industry can be credited to, among others, the growth of the Malaysia hotel industry. According to Tourism Malaysia (2021), the development of hotel industry has been encouraging as the number of hotels has improved to 1,492 in 2000 from 5,339 in 2020. This reflects the growth of the hospitality industry in 
meeting the tourism market demand in Malaysia where the requirement for sufficient workforce is heightened to ensure a competitive delivery of products and services.

Despite these positive growths, the significant problem of high level of turnover still plays a substantial role in hindering the development of the tourism industry as a whole and Malaysian hotel industry specifically (Abdullah et al., 2010; Yan et al., 2021). This situation is in line with the issues encountered by the travel and tourism worldwide, as this problem is felt intensely in the profession of cooking (lomare, Afifi \& Healy, 2020; Young \& Corsun, 2010). Aligning with this situation, the turnover rates in the cooking profession are prevalently high in Malaysian hotel industry as anecdotal evidence showed that chefs tend to job hop frequently as this phenomenon becomes a norm behavior among them in seeking better paying, more job satisfaction and much better opportunities in other organizations (Suhairom et al., 2019; Abdullah et al., 2010). In the same vein, a strong relationship between jobhopping behavior and turnover intention in the food and beverage industry has already been empirically proven (Khatri et al., 2001). This has subsequently put the job-hopping behavior as one of the most crucial factors that caused high turnover rates in the cooking profession. As such, it will be potentially costly and may implicate negatively to the hotel organizations if there are no actions taken to curb this phenomenon of job-hopping and turnover in Malaysia (Johari, Yahya \& Ahmad, 2012). This is because the process of replacement will diminish the resource, decrease the efficiency and effectiveness of daily operations for the continuing staff and thus, risking the capability of hotel organizations to achieve their range of business objectives (Rowley \& Purcell, 2001).

Therefore, the contemporary management must relish the challenge to introduce and implement the needed measures such as an improved quality work life (QWL) and occupational commitment (OC) to counter unwanted turnover among the chefs. QWL and OC is crucial for hotel organizations as they are likely to gain benefit in terms of employing and keeping valuable employees (Daud, 2010; Hanan \& Zainal, 2012; May, Lau \& Johnson, 1999; Simola, 2011) as well as enjoying an exceptional growth and organizational success (Lau \& May, 1998). Based on this premise, it is the aim of this paper to analyse the impacts of QWL and $\mathrm{OC}$ on the job-hopping behavior among the chefs in Malaysia.

\section{Literature Review}

\section{Understanding Job-Hopping Phenomenon}

Owing to the intense competition, heavy pressure and clustered industries, job-hopping has become the trend in today's workforce (Hassan et al., 2020; Zhang \& Shi, 2010). Job-hopping can be defined in two different parts. For the first part of the definition, it revolves around Ghiselli (1974)'s theory of 'hobo syndrome'. Ghiselli (1974) is known as one of the earliest pioneers in designing and developing a concept known as 'hobo syndrome', which is similar to the concept of job-hopping. 'Hobo syndrome' is the tendency of workers with instinctive impulses to move one job to another regardless of logical factors and organized logical thinking. Without apparent rational motives to migrate from one job to another, workers who are unwilling to stay put long may have a strong inclination to try new things or simply because they are enjoying it (Khatri et al., 2001; Saleem, Saleem \& Jalil, 2015).

On the other hand, the second part of the definition relates to the social influences or turnover culture in organizations (Abelson, 1993; Saleem et al., 2015). Turnover culture is the 
shared perception of norm behavior of switching jobs among the organizational workers (Abelson, 1993). Subsequently, this culture affects the decision making of organizational workers whether to switch job or not since the other colleagues are doing the same thing. Interestingly, job hoppers view this norm behavior as essential for their self-fulfillment in terms of work experience, learning new techniques, increase of salaries and obtain higherlevel position (Zhang \& Shi, 2010). Hence, this explains why an employee would feel an increasing pressure to change his or her job if that individual has not done so for a long time as the job-hopping becomes the normal practice especially among the chefs in the food and beverage industry (Khatri et al., 2001).

\section{Quality Work Life}

The development of QWL can be traced back where most studies in the earlier management era from 1970s to 1980s focused on defining the concept empirically (Martel \& Dupuis, 2006). Since it was first introduced, the concept of QWL has gone through numerous processes of evolution that it grew to several distinctive theoretical conceptions during this span of period. For instance, Stjernberg (1977) asserted that other life spheres such as overall life satisfaction, leisure and wellbeing that transcend the working environment should be considered in defining the QWL. On the other hand, Davis (1983) had added the perspective of human dimension towards the economic consideration of the quality of relationship between employees and the total working environment in the conception of QWL.

At the start of 1990s, it can be seen that there is wide-ranging method of defining QWL (Loscocco \& Roschelle, 1991) and more scholars changing their attention on the relationship of QWL and work satisfaction solely since more studies looked into variables such as work security, work involvement, reward system, opportunities for training and career advancement, involvement in decision-making to name a few (Danna \& Griffin, 1999; Lau \& May, 1998). The lack of collective acceptance among the researchers on the conception of QWL continued the first few years of this millennium as the direction of this concept shifting once again with the new measurements were introduced (Daud, 2010). Sirgy et al. (2001) developed one of these measurements of QWL that was based on need satisfaction and spillover theories. This measurement consisted of seven of needs dimensions namely 1 ) health and safety needs; 2 ) economic and family needs; 3 ) social needs; 4) esteem needs; 5 ) actualization needs; 6) knowledge needs; and 7) aesthetic needs. Apart from this, there is also other new measurement that was built upon proposed definition of Quality of Life (QOL) by Martel and Dupuis (2006). They suggested that quality work life should be measured in four contexts of 1 ) the nature of the job; 2) the physical environment of the workplace; 3 ) the psychosocial of conditions of the employees; and 4) organizational management and policies.

This development is illustrative of QWL's dynamic, and it has become crucial due to the rising demands of professional settings (Bagtasos, 2011; Mortazavi et al., 2012; Ong et al., 2019). For instance, Heidarie et al. (2012) posited quality work life generally as a comprehensive plan that improves the employee's fulfillment by preparing them to manage with various management issues in their working environment. For this reason, the studies on quality work life keep expanding and include more combinations of different variables such as work satisfaction, organizational commitment, alienation, work stress, organizational identification, work involvement and work role ambiguity, conflict, and overload (Daud, 2010). In fact, quality work life has been researched in numerous research settings such as 
human resource, banking, marketing managers, teachers and accountants where it has been analysed as independent, mediating, moderating and dependent variables in ranges of research models in order to have better understanding of employee behaviors (Hong, Tan \& Bujang, 2010; Koonmee \& Virakul, 2007; Sirgy et al., 2001; Talebi et al., 2012). Furthermore, most studies and literatures in quality work life also have related to numerous employees' work outcomes that consisted of among others, increased retention and productivity (Koonmee \& Virakul, 2007).

Since the occupational turnover is a crucial and protracted problem within the hospitality industry (Hanan \& Zainal, 2012), Kandasamy and Ancheri (2009a) developed and proposed the dimensions of QWL specifically for the hotel employees. The results revealed that conceptually, QWL can be measured as a multi-dimensional variable consisted of eight dimensions of 1) job characteristics; 2) person-job fit; 3) company image; 4) human resource (HR) policies; 5) work group relationship; 6) physical working conditions; 7) work-life balance and; 8) interaction with customers. The improvement of these dimensions is deemed to be crucial since QWL can have substantial effects on their behavioral responses (Kandasamy \& Ancheri, 2009b; Sirgy, et al., 2012; Sirgy, et al., 2001) such as job satisfaction, organizational commitment, turnover intention and so on. Thus, it is to be postulated that the fulfillment of quality work life will leads to higher job satisfaction (Daud, 2010; Denvir \& McMahon, 1992; Kandasamy \& Ancheri, 2009b; Murray-Gibbons \& Gibbons, 2007; Rowley \& Purcell, 2001; Young \& Corsun, 2010), which led to increasing work engagement and finally to lower jobhopping behavior among the chefs in the hotels. Based on these discussions, it is hypothesized that:

H1: QWL is negatively associated with the job-hopping behavior among the chefs.

\section{Occupational Commitment}

Commitment in the workplace has been proven to be significant predictors of behaviors such as actual performance, organizational citizenship behavior, turnover and absenteeism (Cohen, 2007). Interestingly, the largest part of these studies focused on the organizational commitment even though other forms of commitment such as work motivation, professional commitment, career commitment, occupational commitment and job involvement also have been researched widely (Kim \& Mueller, 2011).

Even though there are many research that gave their own perspectives of commitments, the model of organizational commitment by Meyer and Allen (1991) has successfully incorporated all these perspectives into three recurring themes of organization's affective attachment, the cost perceived in exiting the company, and obligation to remain and stay working with the organization. Interestingly, the three-types of occupational commitment were extended and introduced from Meyer and Allen's (1991) own model of organizational commitment. Klassen et al (2013); Chen et al (2010); McComb (2006); Irving et al (1997) to name a few, have applied the three variables of affective commitment, continuance commitment and normative commitment from the organizational commitment's research into the study of occupational commitment. This only further proves to the fact that there is significant similarity but with a different direction between these two concepts (Cohen, 2007). This is in line with Meyer, Allen and Smith's (1993) definition of occupational commitment as an individual's commitment to a certain line of profession. 
Affective commitment is proposed upon the employees' ability to emotionally identify themselves with the goals of their working place and their preferred working familiarity (Lee et al., 2000). Employees with this type of commitment are likely to further improve themselves in that line of profession since they have the drive and motivation to remain with the job from their emotional connection to it (Simola, 2011). The continuance commitment refers to the risk of perceived costliness if the employees leaving their current professions, which has been highlighted by Irving et al. (1997). The causation for this is they always have the tendency to think that they do not have the space or opportunity to change their line of profession with the perceived limited career choices (Meyer et al., 1993). Apart from this, the employees also need to face with the significant loss of investments and resources such as time, money and energy in sustaining their current career's path if they were to change their profession.

While normative commitment relates on the responsibility of an employee to stay in their line of occupation since there is pressure to do so from the families and colleagues, which may make leaving the job very costly (Irving et al., 1997). This form of commitment also related closely to the employees' proclivity to be actively involves in professional activities and thus, keeping oneself to have awareness on current developments in that line of occupation (Snape et al., 2008). Interestingly, the relative strengths of these three components are different in affecting the occupational withdrawal cognitions of an employee. Affective commitment for example, is all about the desire to be proactive and is probably involving stronger attachment to the profession compared to normative and continuance (Meyer \& Herscovitch, 2001).

Normative commitment, on the other hand, can only be projected to remain until the fulfillment of responsibility and obligation of the profession where the commitment is based on it. In the case of continuance commitment, it is mainly centered on the cost of exiting a certain line of profession. Hence, if there is an opportunity with great benefits to be found, the effect of continuance commitment is expected to dissipate (Snape \& Redman, 2003). Thus, it is hypothesized that when the overall occupational commitment is lowered, it leads to the increment of job-hopping behavior as it is worth mentioning that both constructs were considered as one of important antecedents that causing turnover intentions (Blau \& Lunz, 1998; Khatri et al., 2001; Lee et al., 2000; Meyer et al., 1993).

\section{H1: OC is negatively associated with the job-hopping behavior among the chefs.}

\section{Research Methodology}

The study was conducted among the chefs in the hotel industry, as they are responsible in managing the kitchen operation with the increasing daily responsibility to cut costs and work multi skilling. Chefs are referred to those who hold the upper management position at the kitchen, which consist of Executive Chef, Sous Chef, Junior Sous Chef and Chef de Partie. In order to achieve homogenous sampling, chefs at the 4-star and 5-star rated hotels within the district of Jalan Sultan Ismail, which is also known as the Golden Triangle of Kuala Lumpur are chosen given the similarities in terms of the hectic nature of the location. According to the Rated Tourist Accommodation Premises reported from the Official Portal Ministry of Tourism and Culture Malaysia (2021), a total of 28 hotels are categorized as 5-star rated hotels while 26 hotels are categorized as 4-star rated hotels in Kuala Lumpur. Based on 52 hotels listed, 3 hotels were excluded for the purpose of pilot study where 30 chefs were approached. This is 
done to ensure that the measurements work well with the chefs and yield the data required. In addition, content validity was also addressed by asking the hospitality academicians with years of research experience prior to pilot study being conducted.

After the conclusion of this process, there is a total of 49 hotels remained for this research. According to the preliminary data gathering that is conducted through interviews with five employees of the 3 selected hotels, there is an average of 7 chefs in each hotel. This means that there are 343 chefs for the total population of the current study. This figure is then referred to the Isaac and Michael's (1981) table at $95 \%$ with $\pm 5 \%$ of precision level accordingly. Thus, a minimum of 187 respondents was enough to represent the total population in this study.

For the survey instruments, a close and self-administered questionnaire was developed for a quantitative research design and cross-sectional approach. It consisted of four sections namely QWL, OC, job-hopping behavior and demographic profile. There are 52 items for the first three sections of questionnaire and they are measured using a seven-point Likert scale ranging from 1-very untrue to 7-very true. These items are adapted from studies conducted by Kandasamy and Ancheri (2009a), Meyer et al. (1993) and Khatri et al. (2001). As for the demography section, the items include the star rating of the chef's hotel, position, race, gender, age, educational level, income range, job tenure, number of jobs before of the chef's current position and organizational tenure.

Owing to the hectic nature of the hotel industry and the cooking profession itself as well as the restricted resources such as time, money and workforce, convenience sampling was therefore adopted. A total of 79 usable questionnaires were collected which constitute $42 \%$ of the sample size. This study uses the Statistical Package for the Social Science (SPSS) 42.0 software to run several statistical analyses on the raw data from the questionnaire. The data analysis technique consists of frequency and multiple regression analysis to explain the variance of an individual independent variable ( $Q W L$ and $O C$ ) that influences the dependent variable of job-hopping, which answering the main research objective of this study. Figure 1 shows the research model of this study.

Figure 1. The proposed conceptual framework



\section{Research Findings \\ Reliability Test}

Reliability analysis was performed through Cronbach's alpha. It is revealed that the alpha values for all the variables are ranged from 0.68 to 0.93 (see Table 1). This result had met the level of reliability as recommended by Hinton et al (2004) and Nunnaly (1967). Hence, it can be posited that all the variables are considered reliable. 
Table 1. Cronbach's Alpha Coefficient Study Variables

\begin{tabular}{|l|l|l|l|}
\hline Variable(s) & N & $\begin{array}{l}\text { Number } \\
\text { of Scale } \\
\text { Item (s) }\end{array}$ & $\begin{array}{l}\text { Cronbach's Alpha } \\
\text { Coefficient, } \alpha\end{array}$ \\
\hline QWL & 79 & 28 & .93 \\
\cline { 1 - 1 } OC & & 18 & .75 \\
\cline { 1 - 1 } Job Hopping Behavior & & 6 & .68 \\
\hline
\end{tabular}

\section{Characteristics of the Chefs}

Majority of the respondents are coming from 5-star hotels with $66 \%$. From this, it can be identified that the position of the respondents with $46 \%$ being to the Chef de Partie, followed by $13 \%$ who are Junior Sous Chef. $37 \%$ are Sous Chefs and Executive Chefs is the smallest group at $5 \%$. Most of the chefs in the present study are Malays, which constitutes $78 \%$ of the total respondents. With regards to the gender, males make up most of the respondents at $82 \%$. For the age gap of the chefs, the highest distribution belongs to the age group of 25 to 29 with $32 \%$. Many of the respondents had completed diploma with $42 \%$ and as for the income level, 38\% of the chefs received an income level that ranged at RM4,000 and above. Overall, it is reflected that most of the participants (20\%) in this study have been working in this line of work for between 7 to 9 years. From this data, it is also revealed that $43 \%$ of chefs job-hop at least between once to three times in their career. Finally, it is also indicated that majority of the chefs (51\%) participated in this study have an organizational tenure ranged between 1 to 3 years.

\section{Multiple Regression Analysis}

Table 2 depicted the result of the multiple regression analysis on the relationship between QWL, OC and job-hopping behavior. Result of the model estimation show that the R square value is .218, which means that almost 22 percent of variance in the job-hopping behavior can be significantly explained by QWL and OC.

Table 2. Model Summary

\begin{tabular}{|l|l|l|l|l|}
\hline Model & R Square & $\begin{array}{l}\text { Adjusted } \\
\text { Square }\end{array}$ & $\begin{array}{l}\text { Std. Error of } \\
\text { the Estimate }\end{array}$ & $\begin{array}{l}\text { Standardized } \\
\text { Coefficient, } \beta\end{array}$ \\
\hline QWL & $.218 * * *$ & .198 & .948 & $-.229 *$ \\
\hline OC & & & $-.391^{* * *}$ \\
\hline
\end{tabular}

Note: Confidence Interval, ${ }^{*} p<0.05, * * p<0.01, * * * p<0.001$

At the significant level of $0.05, Q W L$ has negative significant influence on job-hopping behavior with $(\beta=-.244)$. Considering the result, this subsequently means the first hypothesis is accepted. In the case of occupational commitment, the Beta coefficients clearly showed that it had the strongest negative influence on the job-hopping behavior of chefs ( $\beta=-.407$ ) at the significant level of 0.001 . This means that the second hypothesis of this study is also accepted.

\section{Discussion and Conclusion}

The aim of this study is achieved through the analyses conducted and the findings derived in the fulfilment of both research hypotheses, which entails on the impacts of QWL and OC on the job-hopping behavior among the chefs in Malaysia. Specifically, the result did indicate 
QWL as one of the predictors of job-hopping behavior of chefs in Malaysia hotel industry, which lead to the acceptance of the first hypothesis. To a certain extent, this result is consistent with the previous studies where empirically, there is a negative relationship between QWL and turnover intention (Lee et al., 2013; Surienty et al., 2013). In the same vein, the low standardized coefficient of QWL reflects the lack of its importance in impacting the intention of chefs to job hop in the context of Malaysia. This reflects the capacity of hotel organizations in Malaysia to retain the chefs for considerable years of organizational tenure. This may be attributed to the general perceptions among the chefs that their employers have done appropriately in providing a workplace that enables them to meet all the essential career-related needs.

However, it is worth mentioning that the correlation between $\mathrm{OC}$ and the job-hopping behavior is comparably stronger. This means that the $\mathrm{OC}$ is the best predictor in the context of this study. The nature of this finding means that the second hypothesis is also accepted, and this subsequently led to the fulfillment of the research aim. The outcome of significant contribution from OC towards the job-hopping behavior is also in line with the prior studies of Wang et al (2011); Lee et al (2000). Considering that most of the chefs involved in this study have been working in this line of work for 10 to 30 years, it demonstrates their level of commitment where they are working a lot of years under intense pressure and heavy workload. Subsequently, these experiences contributed enormously to most of the chefs as they are emotionally attached to the cooking profession and could relate themselves with the working goals and objectives as they further progress to the top of their career.

Given the nature of the reported findings, it is important to treat them cautiously as there are several limitations that need to be addressed in the future research. It is important to note that the sample size is relatively small to enable a more sophisticated analysis to determine the potential mediation or moderation effects between $\mathrm{QWL}, \mathrm{OC}$ and job-hopping behavior among the chefs. The utilization of convenience sampling also potentially hinders the larger sample size and generalization of the results. Despite this, it is important to note the difficulty associated in collecting enough sample size among the chefs considering their long working hours and rapid demands of their workloads. Furthermore, the relative low percentage of variance explained by both QWL and OC heighten the need for other potential influences such as networking or decision to enter entrepreneurship on the job hopping behavior of chefs (see Azinuddin, Mior-Shariffuddin \& Zain, 2020; Zarhari et al., 2020).

Nevertheless, it is worth mentioning that this study contributes to the tourism and hospitality body of knowledge in providing empirical insights into the dynamics of job-hopping behavior among chefs. The stronger impact of OC highlights the nature of the profession such as long working hours in highly pressurized environment does not push the chefs to job hop and exit from their line of work. In fact, it is posited that the result is more reflective of the chefs to be committed in their career growth. The nature of the result also means that occupational commitment has a significant position in measures such as employee engagement survey and periodic review discussions in identifying individuals with higher tendency to job hop. From this, interventions and policies can be formulated to address the high turnover among the chefs and subsequently reduce the cost borne by the hotels to replace them. 


\section{References}

Abdullah, R., Mohd-Alias, M. A., Zahari, H., Abdul-Karim, N., Abdullah, S. N., Salleh, H., \& Musa, M. F. (2010). The study of factors contributing to chef turnover in hotels in Klang Valley, Malaysia. Asian Social Science, 6(1), 80-85.

Abelson, M. A. (1993). Turnover Cultures. Research in Personnel and Human Resource Management, 11, 339-376.

Azinuddin, M., Mior Shariffuddin, N. S. \& Wan Mohd Zain, W. M. A. (2020). Profiling entrepreneurs inclinations on networking: A case of Small and Medium-Sized Tourism Enterprises (SMTEs) in Terengganu, Malaysia. International Journal of Innovation, Creativity and Change, 13(5), 417-432.

Bagtasos, M. R., (2011). Quality of work life: A review of literature. De La Salle University Business and Economics Review, 20(2), 1-8.

Blau, G. J. \& Lunz, M. E. (1998). Testing the incremental effect of professional commitment on intent to leave ones profession beyond the effects of external, personal and workrelated variables. Journal of Vocational Behavior, 52, 260-269.

Chen, C. C., Lee, M. S., Wu, P. J., \& Lin, X. H. (2010). Antecedent and Employees' Occupational Commitment. In the Proceedings of the Management of Innovation and Technology (ICMIT) IEEE Singapore International Conference.

Cohen, A. (2007). Dynamics between occupational and organizational commitment in the context of flexible labor markets: A review of the literature and suggestions for a future research agenda. Bremen: Inst. Technik und Bildung.

Danna, K., \& Griffin, R. W. (1999). Health and well-being in the workplace: A review and synthesis of the literature. Journal of Management, 25(3), 357-384.

Daud, N. (2010). Investigating the relationship between quality of work life and organizational commitment amongst employees in Malaysian Firms. International Journal of Business and Management, 15(10), 75-82.

Davis, L. E, (1983). Design of new organizations. In: Kolony, H., Beinum, H.V. (Eds.), the Quality of Working Life and the 1980s. Praeger Publisher.

Denvir, A. \& McMahon, F. (1992). Labour turnover in London hotels and the cost effectiveness of preventative measures. International Journal Hospitality Management, 11(2), 143154.

Department of Statistics Malaysia. (2019). Tourism satellite account 2019. Retrieved from https://www.dosm.gov.my/v1/index.php/index.php?r=column/cthemeByCat\&cat=1 11\&bul_id=dEZ6NOdYUDJEWkVxMzdOalY3UUJSdz09\&menu_id=TE5CRUZCblh4ZTZM ODZIbmk2aWRRQT09

Ghiselli, E. E. (1974). Some perspectives for industrial psychology. American Psychologist, 8087.

Hanan, F. A., \& Zainal, A, (2012). The relationship between occupational culture, organization tenure and occupational commitment of chefs in 4 and 5-star Hotels in Kuala Lumpur. In Zainal et al (eds) Current Issues in Hospitality and Tourism Research and Innovations. 205-210. London: Taylor and Francis Group.

Heidarie, A., Askary, P., Saedi, S., \& Gorjian, B. (2012). Relationship between quality of work life, organizational health and commitment with job satisfaction. Life Science Journal, 9(3), 2300-2306.

Hong, K. S., Tan, K. W., \& Bujang, S. (2010). Relationship between work life quality of teachers with work commitment, stress and satisfaction: A Study in Kuching, Sarawak, Malaysia. Jurnal Teknologi, 52, 1-15. 
Irving, P. G., Coleman, D. F., \& Cooper, C. L. (1997). Further assessments of a three-component model of occupational commitment: Generalizability and differences across occupations. Journal of Applied Psychology, 82, 444-452.

Isaac, S., \& Michael, W. B. (1981) Sample size table. Retrieved from http://learningstore.uwex.edu

Johari, J., Yahya, K. K., \& Ahmad, M. N., (2012). Understanding the influence of human resource management practices on intention to stay: Evidence from Malaysia. In the Proceedings of the $3^{\text {rd }}$ International Conference on Economic and Business Research.

Kandasamy, I., \& Ancheri, S, (2009a). WRKLFQUAL: A tool for measuring quality of work life. Research and Practice in Human Resource Management, 17(1), 59-70.

Kandasamy, I., \& Ancheri, S, (2009b). Hotel employees' expectations of QWL: A qualitative study. International Journal of Hospitality Management, 28, 328-337.

Khatri, N., Fern, C. T., \& Budhwar, P, (2001). Explaining employee turnover in an Asian context. Human Resource Management Journal, 11(1), 54-74.

Kim, S. W., \& Mueller, C. W, 2011. Occupational and organizational commitment in different occupational contexts: The Case of South Korea. Work and Occupations, 38(1), 3-36.

Klassen, R., Wilson, E., Siu, A. F. Y., Hannok, W., Wong, M. W., Wongsri, N., Sonthisap, P., Pibuchol, C., Buranachaitavee, Y., \& Jansem, A. (2013). Preservice Teachers' Work Stress, Self-efficacy and Occupational Commitment in Four Countries. European Journal of Psychology of Education, 28(4), 1289-1309.

Koonmee, K., \& Virakul, B. (2007). Ethics, quality of work life, and employee job-related outcomes: A survey of HR and marketing managers in Thai businesses. NIDA Development Journal, 47(4), 67-97.

Lau, R. S. M., \& May, B. E, (1998). A win-win paradigm for quality of work life and business performance. Human Resource Development Quarterly, 9(3), 211-226.

Lee, K., Carswell, J. J., \& Allen, N. (2000). A Meta-Analytic review of occupational commitment: Relations with person- and work-related variables. Journal of Applied Psychology, 85(5), 799-811.

Lee, Y. W., Dai, Y. T., Park, C. G., \& McCreary, L. L. (2013). Predicting quality of work life on nurses intention to leave. Journal of Nursing Scholarship, 45(2), 160-168.

Loscocco, K. A., \& Roschelle, A. R. (1991). Influences on the quality of work and non-work life: Two decades in review. Journal of Vocational Behavior, 39(2), 182-225.

Mac Con Iomaire, M., Afifi, M. F., \& Healy, J. J. (2021). Chefs' perspectives of failures in foodservice kitchens, part 1: A phenomenological exploration of the concepts, types, and causes of food production failure. Journal of Foodservice Business Research, 24(2), 177-214.

Mahamudul Hassan, M., Jambulingam, M., Alagas, E. N., Uzir, M. U. H., \& Halbusi, H. A. (2020). Necessities and ways of combating dissatisfactions at workplaces against the JobHopping Generation Y employees. Global Business Review, 1-26.

Martel, J. P., \& Dupuis, G. (2006). Quality of work life: Theoretical and methodological problems, and presentation of a new model and measuring instrument. Social Indicators Research, 77, 333-368.

May, B. E., Lau, R. S. M., \& Johnson, S. K. (1999). A longitudinal study of quality of quality work life and business performance. South Dakota Business Review, 58(2), 3-7.

McComb, E. D. (2003). An evaluation of the three-component model of occupational commitment among New Zealand general practitioners. Otago Management Graduate Review, 8, 67-87. 
Meyer, J. P., \& Allen, N. J. (1991). A three component conceptualization of organizational commitment. Human Resource Management Review, 1(1), 61-89.

Meyer, J. P., \& Herscovitch, L. (2001). Commitment in the workplace. Toward a general model. Human Resource Management Review, 11, 299-326.

Meyer, J. P., Allen, N. J., \& Smith, C. A. (1993). Commitment to organizations and occupations: Extension and test of a three-component conceptualization. Journal of Applied Psychology, 78, 538-551.

Mortazavi, S., Yazdi, S. V. S., \& Amini, A. (2012). The role of the psychological capital on quality of work life and organization performance. Interdisciplinary Journal of Contemporary Research in Business, 4(2), 206-217.

Murray-Gibbons, R., \& Gibbons, C. (2007). Occupational stress in the chef profession. International Journal of Contemporary Hospitality Management, 19(1), 32-42.

Official Portal Ministry of Tourism and Culture Malaysia (2021). Rated Tourist Accommodation Premises (2021). Retrieved from http://www.motac.gov.my/en/check/hotel?s $=\& n=1 \& v=0$

Ong, J. F. B., Tan, J. M. T., Villareal, R. F. C., \& Chiu, J. L. (2019). Impact of quality work life and prosocial motivation on the organizational commitment and turnover intent of public health practitioners. Review of Integrative Business and Economics Research, 8, 24-43.

Rowley, G., \& Purcell, K., (2001). 'As chefs go, she went': Is labour churn inevitable?. International Journal of Hospitality Management, 20, 163-185.

Saleem, T., Saleem, S., \& Jalil, A. (2015). Unweaving Hobo Syndrome in Banking, health and development sector. Gomal Journal of Medical Sciences, 12(4), 227-232.

Simola, S. (2011). Relationship between occupational commitment and ascribed importance of organizational characteristics. Education + Training, 53(1), 67-81.

Sirgy, M. J., Efraty, D., Siegel, P., \& Lee, D. J. (2001). A new measure of quality work life (QWL) based on need satisfaction and spillover theories. Social Indicators Research, 55, 241302.

Sirgy, M. J., Reilly, N. P., Wu, J., \& Efraty, D. (2012). Review of research related to quality work life (QWL) programs. In Land, K. C. (Ed.) Handbook of Social Indicators and Quality of Research. 297-311. Netherland: Springer.

Snape, E., \& Redman, T. (2003). An evaluation of a three component model of occupational commitment: Dimensionality and consequences among United Kingdom human resource management specialists. Journal of Applied Psychology, 88, 152-159.

Stjernberg, T. (1977). Organizational change and quality of life. Stockholm: EFI.

Suhairom, N., Musta'amal, A. H., Mohd Amin, N. F., Kamin, Y., \& Abdul Wahid, N. H. (2019). Quality culinary workforce competencies for sustainable career development among culinary professionals. International Journal of Hospitality Management, 81, 205-220.

Surienty, L., Ramayah, T., Lo, M. C., \& Tarmizi, A. N. (2013). Quality of work life and turnover intention: A Partial Least Square (PLS) approach. Social Indicators Research, 1-16.

Talebi, B., PakdelBonab, M., Zemestani, G., \& Aghdami, N. (2012). Investigating the relationship between the employee's quality of work life (QWL) and their effectiveness in banking. European Journal of Experimental Biology, 2(5), 1839-1842.

Tourism Malaysia (2021). Malaysia tourism data. Retrieved from http://mytourismdata.tourism.gov.my

Wang, L., Tao, H., Ellenbacker, C. H., \& Liu, X. (2011). Job satisfaction, occupational commitment and intent to stay among Chinese nurses: A cross sectional questionnaire survey. Journal of Advanced Nursing, 539-549. 
Yan, Z., Mansor, Z. D., Choo, W. C., \& Abdullah, A. R. (2021). Mitigating effect of psychological capital on employees' withdrawal behavior in the presence of job attitudes: Evidence from five-star hotels in Malaysia. Frontiers in Psychology, 12, 1-14.

Young, C. A., \& Corsun, D. L. (2010). Burned! the impact of work aspects, injury, and job satisfaction on unionized chefs' intentions to leave the cooking occupation. Journal of Hospitality and Tourism Research, 34(1), 78-102.

Zarhari, N. A. A., Azinuddin, M., Mior Shariffuddin, N. S. \& Wan Mohd Zain, W. M. A. (2020). The influence of internal factors and motivation on the decision to enter entrepreneurship. International Journal of Innovation, Creativity and Change, 13(5), 195-212.

Zhang, P. A., \& Shi, M. M. (2010). The analysis of job-hopping by evolutionary game theory. In the Proceedings of the International Conference on Management and Service Science (MASS) 2010 IEEE Wuhan. 